\title{
Swotting up on Genetic Divergence of Cucumber (Cucumis sativus L.)
}

\author{
Amrita Kumari* and Anand K. Singh \\ Department of Horticulture, Institute of Agricultural Sciences, \\ Banaras Hindu University, Varanasi - 221 005, U.P., India \\ *Corresponding author
}

\begin{tabular}{|l|}
\hline Ke y w o r d s \\
Genetic diversity, \\
cucumber (Cucumis \\
sativus L.), \\
Recombinants, \\
Traits and \\
phenotypic \\
selection etc. \\
\hline Article Info \\
\hline $\begin{array}{l}\text { Accepted: } \\
\text { 26 November } 2019 \\
\text { Available Online: } \\
\text { 10 December } 2019\end{array}$
\end{tabular}

\section{Introduction}

Evaluation of 19 diverse genotypes of cucumber was carried out in a randomized block design for studying genetic divergence. Presence of wide genetic diversity, among the 19 genotypes studied was confirmed by using the powerful tool of Mahalanobis $\mathrm{D}^{2}$ statistic. Based on the interactions in genetic distances 19 genotypes of cucumber got grouped into five separate clusters inferring that the genetic divergence between them was quite plentiful. The mode of distribution of genotypes into various clusters, from different ecogeographical regions viz. Purvanchal and Bihar, was at random indicating that geographical distribution and genetic diversity were not related and geographical distribution of the cultivars did not significantly contribute to genetic divergence. A random pattern of distribution of genotypes into five clusters was observed from different geographical locations, also demonstrating that geographical isolation may not be the only factor causing genetic diversity. Lack of parallelism between genetic diversity and geographical distance stipulates that forces other than geographical origins, such as spontaneous variation, natural and artificial selection, exchange of genetic stocks and genetic drift are liable for genetic diversity. Among the five clusters, the maximum number of genotypes was found in cluster II, this implies that it contributed maximum to the genetic divergence. Cluster IV and Cluster V was found to be mono genotypic. Such random clustering pattern will help in broadening the existing genetic base and may produce novel genotypes with seamlessly unknown combinations. The highest intra-cluster distance was observed for cluster III (737.77) and the lowest for cluster IV and V (0.00). The maximum distance at inter-cluster level was observed between cluster III and V (3598.79) which may serve as a potential genotype for hybridization programme. Among the five clusters, cluster II, cluster IV and cluster $\mathrm{V}$ had high mean value for many characters studied. The exploitation of intercrossing the genotype of these clusters may result in an enlargement of a spectrum of variability facilitating the selection for profitable yield. Ranking $\mathrm{D}^{2}$ value revealed that contribution of average fruit weight was highest towards genetic divergence $(47.37 \%)$ followed by test weight $(39.18 \%)$, fruit length $(5.85$ $\%)$, fruit yield in $\mathrm{kg} / \mathrm{plant}(2.34 \%)$ and number of fruits per plant $(1.75 \%)$. Hence, these characters could be exploited for further improvement by phenotypic selection. 
The Cucurbitaceae is a monophyletic family with the most species used as human food. Cucumis sativus is one of the cultivated species of the genus Cucumis which has experienced the most profound study in recent years. Cucumber is assumed to have originated in India, where it had been under cultivation for the last 3000 years (Che et al. 2019; Renner et al. 2007). India possesses a rich diversity of Cucumis sativus and related species, differing widely in botanical and agronomical traits. China is considered to be the secondary centre of origin (Staub et al., 1999). Commercially cucumber is cultivated all over South Asian region. Besides large number of high yielding cultivars many landraces and wild forms have also been reported in cucumber (Sebastian et al., 2010) but it has not been exploited to a greater extent.

The major constraints in achieving higher and profitable productivity of cucumber are lack of exploitable genetic variability, absence of appropriate genotypes for different cropping systems, sensitivity to biotic and abiotic stresses, non-availability of quality seeds of improved varieties and narrow genetic base, due to repeated usage of few parents with high degree of pertinence in crossing programmes. Limited variability has been exploited in varietal development programmes in cucumber. Many breeding attempts have been made to improve the yield level of this crop and to break the yield plateau. Genetic variability and divergence present in the germplasm are prerequisites for any breeding programme. The proper estimate of nature and magnitude of diversity in a crop is essential to infer about the extent of variation available for yield and yield attributing traits. Knowledge on genetic divergence among the available germplasm assists a plant breeder for the selection of superior parents for hybridization. Genetically diverse parents are supposed to provide desirable segregants. It is an established fact that the selection of more diverse parents triggers greater chances of obtaining high heterotic $\mathrm{F}_{1} \mathrm{~s}$ and wide range of variability in the segregating generation (Arunachalam, 1981). Multivariate analysis by means of Mahalanobis's $D^{2}$ statistic is a robust implement in quantifying the degree of divergence at the phenotypic level. Keeping in view the above fact the present investigation was commenced to assess the nature and magnitude of genetic divergence among 19 genotypes of cucumber. This type of study would be useful for the breeder in selecting genetically and economically desirable genotypes for insertion in the breeding programme for desired improvements.

\section{Materials and Methods}

\section{Experimental material}

The experiment was conducted at the experimental field of Vegetable Research Farm of Department of Horticulture, Institute of Agricultural Sciences, Banaras Hindu University, Varanasi. 19 genotypes of cucumber were included in our experiment from different eco-geographical regions viz. Purvanchal and Bihar. Genotypes with their sources are presented in the Table 1.

\section{Technical details}

All genotypes were examined for 22 quantitative characters. The experimental design followed was Randomized Block Design and each line was replicated three times with a spacing of $60 \mathrm{~cm}$ between plant to plant and $150 \mathrm{~cm}$ between row to row. Five plants were selected from each replication. All essential precaution was considered to maintain a uniform plant population in each treatment per replication. All suggested package of practices were followed to raise the good crop. 


\section{Statistical analysis}

Data was administered to statistical analysis. For statistical analysis mean of the nineteen genotypes were examined statistically by the method summarized by Ostle (1966). An ANOVA (analysis of variance) was prosecuted to provide the significant differences between different characters by the method of Cochran and Cox (1957). The level of significance was tested at $5 \%$ and $1 \%$ using F- table values outlined by Fisher and Yates (1963). The genetic diversity between the genotypes was determined using Mahalanobis $\mathrm{D}^{2}$ statistics (1936) and grouping of genotypes into clusters was executed following Tocher's method (Rao, 1952). On the contribution of individual characters regarding divergence in all the combinations of the genotypes, each character was ranked on the basis of di $=$ Yij - Yik values. Rank 1 was prescribed to the highest mean difference. The per cent contribution was calculated by keeping in mind total number of combination as 100 per cent.

\section{Results and Discussion}

\section{$D^{2}$ analysis}

On the basis of $\mathrm{D}^{2}$ values, the 19 genotypes were categorized into five highly divergent clusters. The constituent of the clusters with their source are shown in (Table 2; Fig. 1). The germplasm was so divergent, that only seven genotypes were grouped in cluster II and six genotypes in cluster I. The genotypes YRCU-102-09-02 and Gujarat Kheera-01 were so divergent in all the characters that they had to be given the status of a separate cluster (Table 2). This cluster comprising of one genotype with specific valuable traits and other genotypes falling in the highly divergent groups will help in broadening the existing genetic base and may produce novel genotypes with seamlessly unknown combinations. The close scrutiny of Table 2 clearly showed that although the genotypes were selected from different sources, they got grouped in different clusters i.e. genotypes did not cluster according to geographical distributions. Similar results were affirmed by Hasan et al., (2015) while working on seven genotypes of commercial cucumber. To establish the actual location of origin of a genotype is troublesome. To preserve the real identity of the genotypes requires great effort because of free and frequent exchange of genetic material among the crop improvement programme in the country. Furthermore, the incorporation of genes from varied sources may be one of the reasons for losing the basic geographical identity of the genotype. The dissimilarity between genetic diversity and geographical distance stipulates that forces other than geographical origins, such as spontaneous variation, natural and artificial selection, exchange of genetic stocks and genetic drift are liable for genetic diversity. In addition to this influence of environment and genotype $\mathrm{x}$ environment interaction on clustering pattern may be another reason for differential gene expression.

\section{Intra and Inter-cluster distances}

The cluster divergence was manifested by the high inter-cluster and low intra-cluster $\mathrm{D}^{2}$ values (Table 2). The intracluster and intercluster $\mathrm{D}^{2}$ values among 19 genotypes presented in Table 2 revealed that cluster IV and $\mathrm{V}$ showed minimum intra-cluster $\mathrm{D}^{2}$ value $(0.00)$, whereas, maximum intra-cluster $\mathrm{D}^{2}$ value (737.77) was shown by cluster III indicated that very diverse genotypes are included in this cluster and were as a result of both natural and artificial selection forces among the genotypes. The statistical distances among the clusters based on $\mathrm{D}^{2}$ values are also presented diagrammatically (Fig. 2). Minimum inter-cluster $\mathrm{D}^{2}$ value was noted between the clusters I and IV (641.81) 
specified that close relationship among the genotypes included in these clusters. Maximum inter-cluster $\mathrm{D}^{2}$ values were detected between the clusters III and V (3598.79). This specified that the genotypes included in these clusters can be used as a parent in the hybridization programme to get higher heterotic hybrids from the segregating population. Punithae et al., (2012) also explained the phenomenon of parallelism and similar intra and inter-cluster distances while working on 41 diverse genotypes of cucumber (Table 3).

Table.1 List of genotypes understudy

\begin{tabular}{|c|c|c|}
\hline S.No. & Name of the genotypes & Source \\
\hline $\mathbf{1}$ & Shiva & Department of Horticulture, BHU \\
\hline $\mathbf{2}$ & Moti & Department of Horticulture, BHU \\
\hline $\mathbf{3}$ & Prasad-100 & Department of Horticulture, BHU \\
\hline $\mathbf{4}$ & PCUC-09 & IIVR, Varanasi \\
\hline $\mathbf{5}$ & Kalyanpur Green & IIVR, Varanasi \\
\hline $\mathbf{6}$ & Pahari & Department of Horticulture, BHU \\
\hline $\mathbf{7}$ & Varsha Rani & Department of Horticulture, BHU \\
\hline $\mathbf{8}$ & Kheera Number 40 & Department of Horticulture, BHU \\
\hline $\mathbf{9}$ & Anupriya & Department of Horticulture, BHU \\
\hline $\mathbf{1 0}$ & Gujrat Kheera-01 & BAU, Bihar \\
\hline $\mathbf{1 1}$ & Pant Kheera- 01 & Department of Horticulture, BHU \\
\hline $\mathbf{1 2}$ & S-4 & Department of Horticulture, BHU \\
\hline $\mathbf{1 3}$ & CS-1 & Department of Horticulture, BHU \\
\hline $\mathbf{1 4}$ & Heera & Department of Horticulture, BHU \\
\hline $\mathbf{1 5}$ & Vinayak- 512 & Department of Horticulture, BHU \\
\hline $\mathbf{1 6}$ & Vinayak -100 & Department of Horticulture, BHU \\
\hline $\mathbf{1 7}$ & VRCU-102-09-02 & IIVR, Varanasi \\
\hline $\mathbf{1 8}$ & Summer Express & Department of Horticulture, BHU \\
\hline $\mathbf{1 9}$ & Messina Green Long & BAU, Bihar \\
\hline
\end{tabular}

Table.2 Clustering pattern of 19 genotypes of cucumbers based on $\mathrm{D}^{2}$ analysis

\begin{tabular}{|c|c|l|}
\hline Cluster & $\begin{array}{c}\text { Number of } \\
\text { genotypes }\end{array}$ & \multicolumn{1}{|c|}{ Name of genotypes } \\
\hline I & 6 & Moti, Vinayak, S-4, Pant Kheera-01, Heera, Anupriya \\
\hline II & 7 & $\begin{array}{l}\text { Kheera Number-40, Shiva, Vinayak-100, Varsha Rani, Kalyanpur Green, } \\
\text { CS- 1 }\end{array}$ \\
\hline III & 4 & PCUC-09, Summer Express, Pahari, Messina Green Long \\
\hline IV & 1 & YRCU-102-09-02 \\
\hline V & 1 & Gujarat Kheera-01 \\
\hline
\end{tabular}


Table.3 Intercluster and intracluster distances among five clusters in cucumber (Tocher method)

\begin{tabular}{|c|c|c|c|c|c|}
\hline Cluster & Cluster I & Cluster II & Cluster III & Cluster IV & Cluster V \\
\hline Cluster I & 303.41 & 1218.44 & 754.58 & 641.81 & 2292.19 \\
\hline Cluster II & & 644.40 & 1677.13 & 1984.89 & 2874.43 \\
\hline Cluster III & & & 737.77 & 1635.48 & $\mathbf{3 5 9 8 . 7 9}$ \\
\hline Cluster IV & & & & $\mathbf{0}$ & 1939.49 \\
\hline Cluster V & & & & & $\mathbf{0}$ \\
\hline
\end{tabular}

Table.4 Cluster mean of characters towards divergence in nineteen genotypes of cucumber

\begin{tabular}{|c|c|c|c|c|c|}
\hline \multirow[t]{2}{*}{ Characters } & \multicolumn{5}{|c|}{ Clusters } \\
\hline & $\mathbf{I}$ & II & III & IV & $\mathbf{V}$ \\
\hline Days to 50 per cent germination & 3.389 & 3.810 & 3.583 & 3.000 & 3.333 \\
\hline Vine length $(\mathrm{cm})$ & 96.367 & 102.329 & 79.542 & 77.333 & 108.000 \\
\hline Number of primary branches per vine & 4.022 & 3.386 & 3.417 & 4.867 & 4.000 \\
\hline Intermodal length $(\mathrm{cm})$ & 6.531 & 7.130 & 6.402 & 7.667 & 10.667 \\
\hline Number of nodes per vine & 31.522 & 33.105 & 29.117 & 27.333 & 42.533 \\
\hline $\begin{array}{l}\text { Number of node at which first staminate } \\
\text { flower appears }\end{array}$ & 6.272 & 5.481 & 5.767 & 5.067 & 5.067 \\
\hline $\begin{array}{l}\text { Number of node at which first pistillate } \\
\text { flower appears }\end{array}$ & 8.800 & 8.910 & 9.800 & 5.467 & 18.400 \\
\hline Days to first staminate flowering & 37.200 & 35.514 & 36.250 & 33.000 & 36.067 \\
\hline Days to 50 per cent staminate flowering & 39.033 & 38.067 & 38.300 & 35.333 & 39.067 \\
\hline Days to first pistillate flowering & 44.767 & 43.262 & 44.100 & 38.200 & 49.000 \\
\hline Days to 50 per cent pistillate flowering & 50.056 & 49.657 & 48.133 & 41.200 & 51.867 \\
\hline Number of staminate flowers per plant & 288.986 & 297.085 & 297.038 & 256.883 & 249.503 \\
\hline Number ofpistillate flowers per plant & 11.766 & 13.700 & 12.408 & 11.633 & 10.533 \\
\hline Sex ratio & 24.839 & 22.010 & 24.258 & 22.100 & 23.733 \\
\hline Days to first fruit picking & 60.056 & 59.238 & 60.083 & 57.667 & 66.333 \\
\hline Number of fruits per plant & 7.889 & 9.419 & 7.933 & 7.867 & 7.133 \\
\hline Fruit length $(\mathrm{cm})$ & 12.633 & 14.385 & 12.467 & 11.667 & 26.933 \\
\hline Fruit width $(\mathrm{cm})$ & 3.711 & 4.440 & 3.882 & 3.830 & 3.093 \\
\hline Average fruit weight $(\mathrm{g})$ & 127.822 & 173.501 & 120.668 & 119.900 & 130.800 \\
\hline Fruit Yield (kg/plant) & 0.997 & 1.644 & 0.971 & 0.943 & 0.933 \\
\hline Fruit Yield (q/ha) & 110.925 & 182.514 & 108.039 & 104.803 & 103.623 \\
\hline Test weight (g) & 2.942 & 2.954 & 3.428 & 2.260 & 2.157 \\
\hline
\end{tabular}


Table.5 Contribution of each character to divergence

\begin{tabular}{|l|c|c|}
\hline \multicolumn{1}{|c|}{ Sources } & Times ranked 1 & Contribution per cent \\
\hline Days to 50 per cent germination & 0 & 0.01 \\
\hline Vine length (cm) & 1 & 0.58 \\
\hline Number of primary branches per vine & 0 & 0.01 \\
\hline Intermodal length (cm) & 0 & 0.01 \\
\hline Number of nodes per vine & 0 & 0.01 \\
\hline $\begin{array}{l}\text { Number of node at which first staminate } \\
\text { flower appears }\end{array}$ & 0 & 0.01 \\
\hline $\begin{array}{l}\text { Number of node at which first pistillate } \\
\text { flower appears }\end{array}$ & 1 & 0.58 \\
\hline Days to first staminate flowering & 0 & 0.01 \\
\hline Days to 50 per cent staminate flowering & 0 & 0.01 \\
\hline Days to first pistillate flowering & 0 & 0.01 \\
\hline Days to 50 per cent pistillate flowering & 0 & 0.01 \\
\hline Number of staminate flowers per plant & 3 & 1.75 \\
\hline Number of pistillate flowers per plant & 0 & 0.01 \\
\hline Sex ratio & 0 & 0.01 \\
\hline Days to first fruit picking & 1 & 0.58 \\
\hline Number of fruits per plant & 3 & 1.75 \\
\hline Fruit length (cm) & 10 & 5.85 \\
\hline Fruit width (cm) & 0 & 0.01 \\
\hline Average fruit weight (g) & 81 & 47.37 \\
\hline Fruit Yield (kg/plant) & 4 & 2.34 \\
\hline Fruit Yield (q/ha) & 0 & 0.01 \\
\hline Test weight (g) & 67 & 39.18 \\
\hline & & \\
\hline
\end{tabular}

Fig.1 Clustering pattern in cucumber genotypes by Tocher method

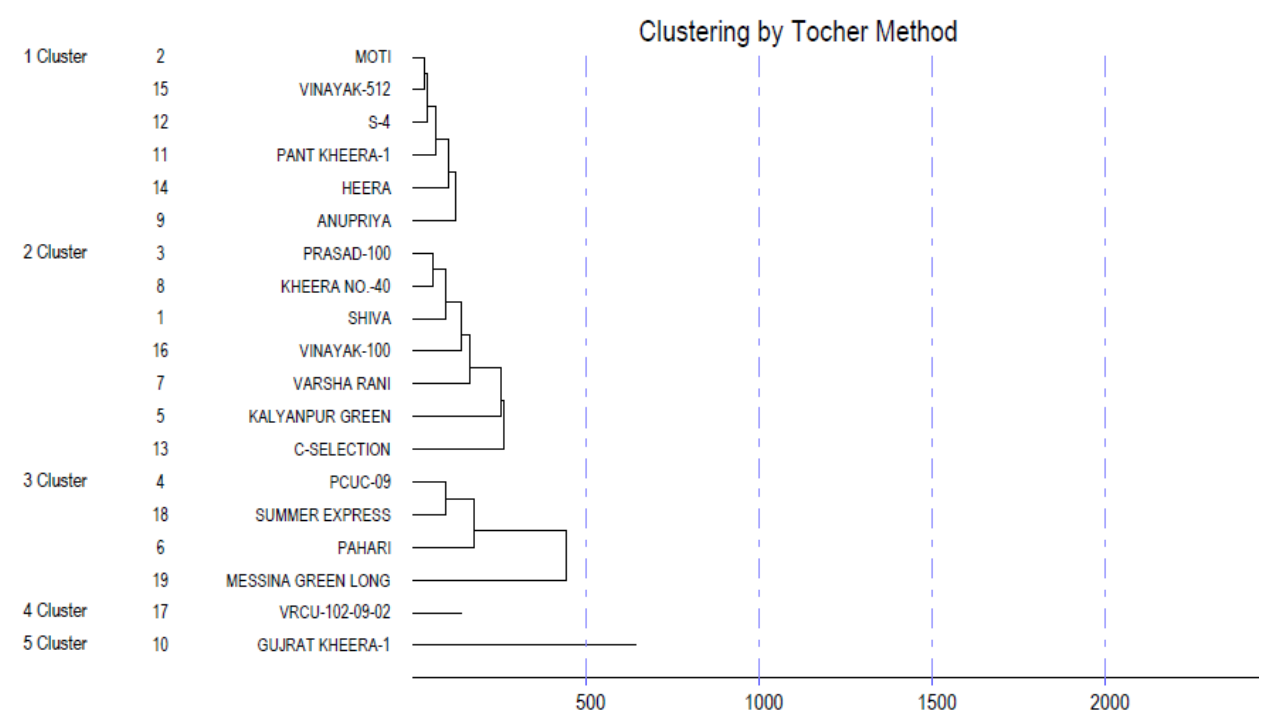


Fig.2 Mahalanobis Tocher distance (not to scale)

\section{Tocher Method}

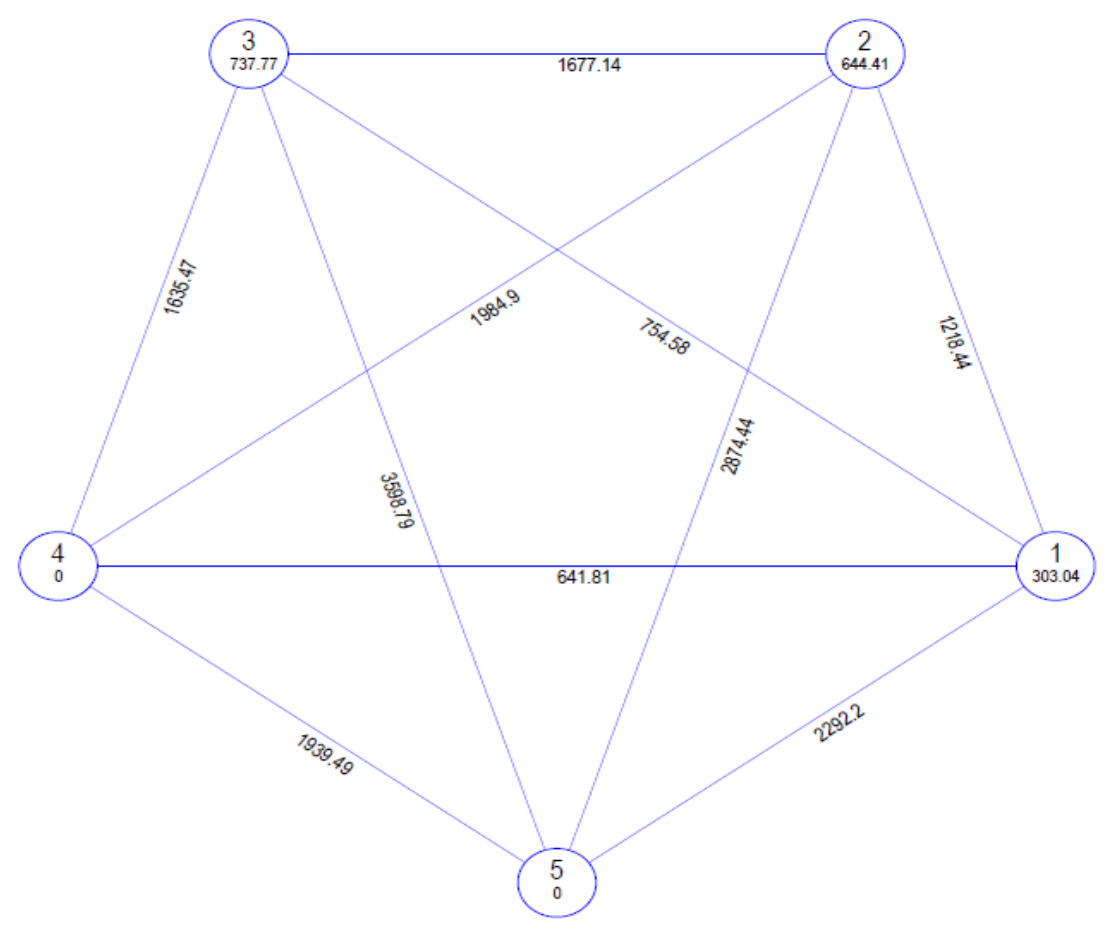

Mahalnobis Euclidean Disatnce (Not to the Scale)

Fig.3(a) Relative contributions of characters towards genetic divergence

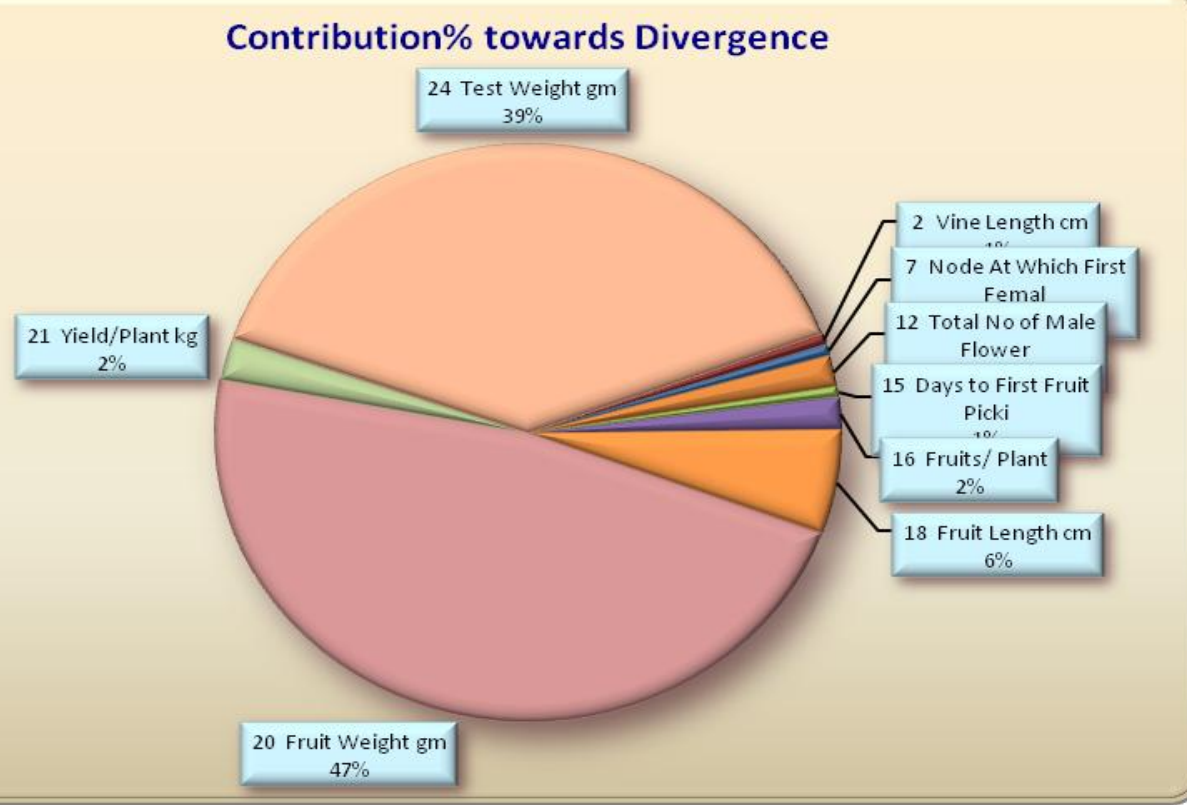


Fig.3(b) Relative contributions of characters towards genetic divergence

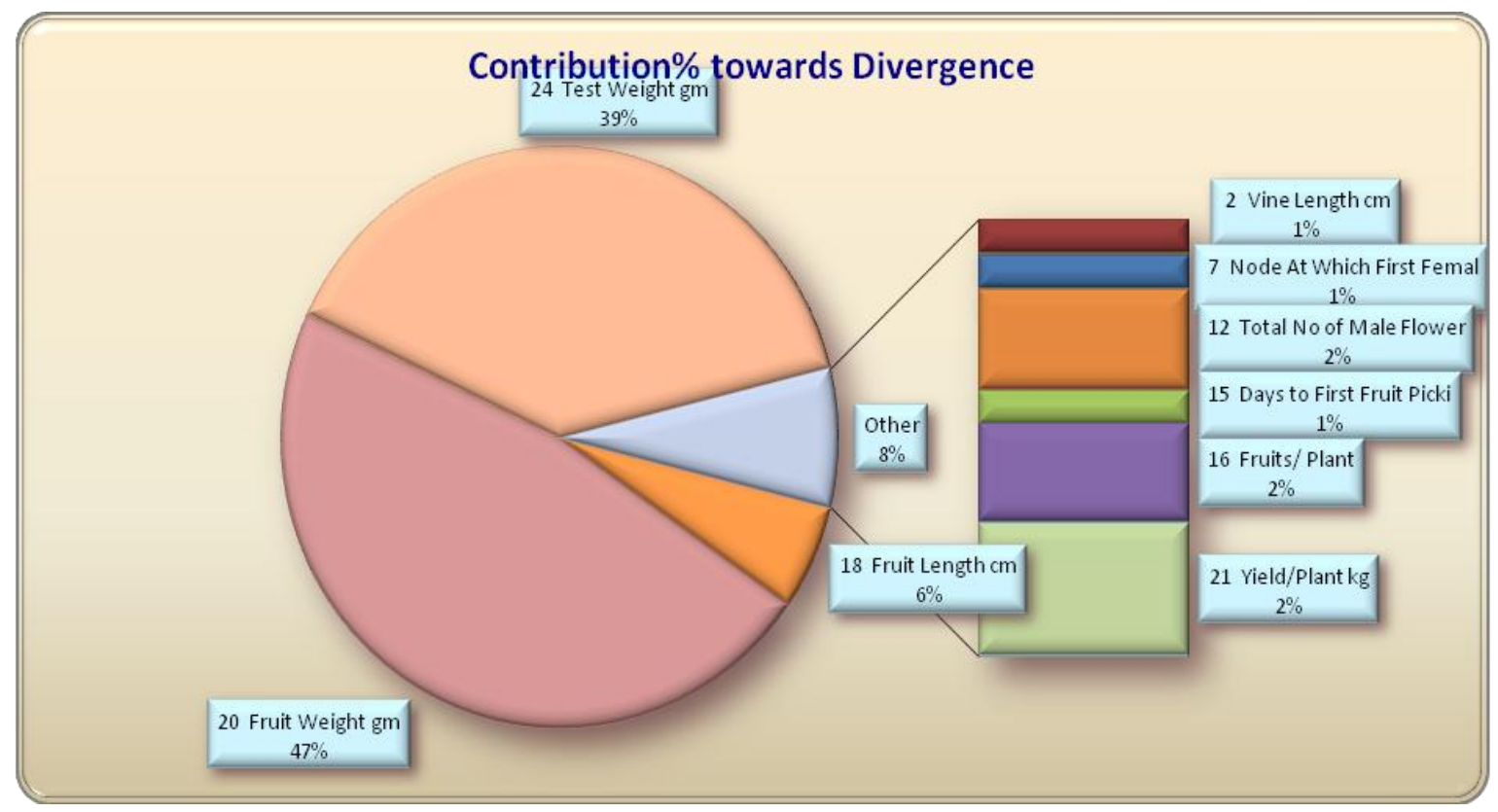

\section{Cluster mean analysis}

Cluster mean analysis of 19 genotypes (Table 4) proclaimed that the mean value of clusters varied in magnitude for all the 22 characters and also revealed the best cluster for various characters. Genotypes in Cluster II recorded maximum value for fruit yield (182.5 q/ha), average fruit weight $(173.5 \mathrm{~g})$, fruit width (4.4 $\mathrm{cm})$, number of fruits per plant (9.41), number of pistillate flower per plant (13.70) and lowest mean value for sex ratio (22.010). Cluster III exhibited the highest mean value for test weight $(3.42 \mathrm{~g})$ and the lowest mean value for the internodal length (6.402). Cluster IV showed the highest mean values for the number of primary branches per vine (4.867) and lowest mean value for days to $50 \%$ germination (3.00), number of nodes at which first pistillate flower appears (5.467), days to first pistillate flowering (38.200), days to $50 \%$ pistillate flowering (41.200), and days to first fruit picking (57.667).

Cluster V exhibited the highest mean values for vine length $(108 \mathrm{~cm})$, number of nodes per vine $(42.53)$ and fruit length $(26.93 \mathrm{~cm})$. This is an agreement with the result of Sharma $e t$ al. 2006. In order to fulfill the aim of breeding, among the different clusters, the breeder can select potential lines as a parent in hybridization programme.

\section{Relative contribution on the characters to genetic divergence}

The relative contribution of various characters to the total genetic divergence (Table 5; Figure 3) was evaluated by the use of $\mathrm{D}^{2}$ statistic. The character showing a higher contribution to the divergence was given lesser rank and vice versa. Such criteria were also standardized by Punitha et al., (2012). They worked on 41 diverse genotypes of cucumber collected from different district of Tamilnadu and suggested that based on ranking D2 values tender fruit yield per vine, tender fruit girth, tender fruit weight and number of tender fruit per vine contributed high divergence. The present study revealed that contribution of average fruit weight was highest towards genetic divergence $(47.37 \%)$, 
followed by test weight $(39.18 \%)$, fruit length $(5.85 \%)$, fruit yield in $\mathrm{kg} /$ plant $(2.34$ $\%)$ and number of fruits per plant $(1.75 \%)$.

In conclusion, considerable diversity was perceived among the genotypes collected from different eco-geographical regions viz. Purvanchal and Bihar. If a breeding programme is aimed for higher yield, then genotypes from cluster II can be selected as a parent which showed highest mean for yield per plant along with higher average fruit weight, fruit width and total number of fruits per plant. If a breeding programme is aimed for the small-fruited group, a selection from cluster IV will be highly effective; and to breed long fruited varieties having some demand in a specific region of India, selection from cluster $\mathrm{V}$ will be fruitful. The genotypes of a highly divergent cluster may also be exploited in a breeding programme for the development of high yielding varieties with desirable traits and could also be exploited in heterosis breeding programme for the development of $\mathrm{F}_{1}$ hybrids with marvellous yield and quality characters. In order to select genetically diverse genotypes for hybridization, the material should be screened for the important traits like average fruit weight; test weight, fruit length and fruit yield, and these characters could be exploited for further improvement by phenotypic selection.

\section{References}

Che, G., and Zhang, X. 2019. Molecular basis of cucumber fruit domestication. Current opinion in plant biology, 47: 38-46.

Cochran, W. G. and Cox, O. M. 1957. Experimental Designs. John Wiley and Sons, incorporation, New York, pp. 611.

Fisher, R. A. and Yates, F. 1963. Statistical tables for biological, agricultural and medical research. 6th Ed. Oliver and Boyd, Edinburgh and London X, 146 P. Preis 42 s net. Biometrische Zeitschrift, 13(4): 285

Hasan, R., Hossain, M. K., Alam, N., Bashar, A., Islam, S., and Tarafder, M. J. A. 2015. Genetic divergence in commercial cucumber (Cucumis sativus L.) genotypes. Bangladesh Journal of Botany, 44(2): 201-207.

Mahalanobis, P.C. 1936. On the Generalised Distance in Statistics. Proceedings of the National Institute of Sciences of India, 2: 49-55.

Ostle, B. 1966. Statistics in research. Oxford and IBH. pp. 363-370.

Punitha, A., Bharathi, A. and Devi, D. S. 2012. Studies on genetic divergence on cucumber (Cucumis sativus L.). Asian Journal of BioScience, 7(2): 169-173.

Rao, C.R. 1952. Advanced Statistical Methods in Biometric Research. John Wiley and Sons, Incorporation. New York. pp.390.

Renner, S.S., Schaefer, H. and Kocyan A. 2007. Phylogenetics of Cucumis (Cucurbitaceae): cucumber (Cucumis sativus L.) belongs in an Asian/ Australian clade far from melon (Cucumis melo). BMC Evol Biol, 7: 58.

Sebastian, P., Schaefer, H., Telford, I. R., and Renner, S. S. 2010. Cucumber (Cucumis sativus) and melon (Cucumis melo) have numerous wild relatives in Asia and Australia, and the sister species of melon is from Australia. Proceedings of the National Academy of Sciences, 107(32): 14269-14273.

Sharma, H. R. and Deepa Sharma. 2006. Genetic divergence for yield and yield contributing traits in cucumber (Cucumis melo L.). Journal of Horticultural Sciences, 1(2): 141-143.

Staub, J. E., Serquen, F. C., Horejsi, T., and Chen, J. F. 1999. Genetic diversity in cucumber (Cucumis sativus L.): IV. An 
evaluation of Chinese germplasm. Genetic Resources and Crop Evolution, 46(3): 297-310.

Yadav, J. R., Mishra, G., Shukla, N. S., Singh, H. C., Singh, B. and Srivastava,
J. P. 2005. Genetic divergence in long melon (Cucumis melo var. utillissimus). Progressive Agriculture, 5(1/2): 50-52.

\section{How to cite this article:}

Amrita Kumari and Anand K. Singh. 2019. Swotting up on Genetic Divergence of Cucumber (Cucumis sativus L.). Int.J.Curr.Microbiol.App.Sci. 8(12): 2802-2811. doi: https://doi.org/10.20546/ijcmas.2019.812.328 